\title{
Gene expression varies within and between enzootic and epizootic lineages of Batrachochytrium dendrobatidis (Bd) in the Americas
}

\author{
McDonald, C. A.; Ellison, Amy; Toledo, L. F.; James, T. Y.; Zamudio, Kelly R.
}

\section{Fungal Biology}

DOI:

10.1016/j.funbio.2019.10.008

Published: 01/01/2020

Peer reviewed version

Cyswllt i'r cyhoeddiad / Link to publication

Dyfyniad o'r fersiwn a gyhoeddwyd / Citation for published version (APA):

McDonald, C. A., Ellison, A., Toledo, L. F., James, T. Y., \& Zamudio, K. R. (2020). Gene expression varies within and between enzootic and epizootic lineages of Batrachochytrium dendrobatidis (Bd) in the Americas. Fungal Biology, 124(1), 34-43.

https://doi.org/10.1016/j.funbio.2019.10.008

\footnotetext{
Hawliau Cyffredinol / General rights

Copyright and moral rights for the publications made accessible in the public portal are retained by the authors and/or other copyright owners and it is a condition of accessing publications that users recognise and abide by the legal requirements associated with these rights.

- Users may download and print one copy of any publication from the public portal for the purpose of private study or research.

- You may not further distribute the material or use it for any profit-making activity or commercial gain

- You may freely distribute the URL identifying the publication in the public portal?
}

Take down policy

If you believe that this document breaches copyright please contact us providing details, and we will remove access to the work immediately and investigate your claim. 


\section{Original Article}

2 Title: Gene expression varies within and between enzootic and epizootic lineages of

3 Batrachochytrium dendrobatidis $(B d)$ in the Americas

4

5 Author names and affiliations: McDonald CA, ${ }^{a^{*}}$ Ellison $A R,{ }^{b}$ Toledo $L F,{ }^{c}$ James $T Y,{ }^{d}$

6 Zamudio $\mathrm{KR}^{\mathrm{a}}$

7 aDepartment of Ecology and Evolutionary Biology, Cornell University, Ithaca, New York $8 \quad 14850$

9 bSchool of Natural Sciences, Bangor University, Bangor, LL57 2UW, UK

10 'Departamento de Biologia Animal, Instituto de Biologia, Universidade Estadual de

11 Campinas, Campinas, São Paulo, Brazil

12 dDepartment of Ecology and Evolutionary Biology, University of Michigan, Ann Arbor,

13 Michigan 48109

Corresponding author: Cait McDonald, Department of Ecology and Evolutionary 


\section{ABSTRACT}

While much research focus is paid to hypervirulent fungal lineages during emerging infectious disease outbreaks, examining enzootic pathogen isolates can be equally fruitful in delineating infection dynamics and determining pathogenesis. The fungal pathogen of amphibians, Batrachochytrium dendrobatidis (Bd), exhibits markedly different patterns of disease in natural populations, where it has caused massive amphibian declines in some regions, yet persists enzootically in others. Here we compare in vitro gene expression profiles of a panel of $B d$ isolates representing both the enzootic $B d$-Brazil lineage, and the more recently diverged, panzootic lineage, $B d$-GPL. We document significantly different lineage-specific and intralineage gene expression patterns, with $B d$-Brazil upregulating genes with aspartic-type peptidase activity, and Bd-GPL upregulating CBM18 chitin-binding genes, among others. We also find pronounced intralineage variation in membrane integrity and transmembrane transport ability within our $B d-G P L$ isolates. Finally, we highlight unexpectedly divergent expression profiles in sympatric panzootic isolates, underscoring microgeographic functional variation in a largely clonal lineage. This variation in gene expression likely plays an important role in the relative pathogenesis and host range of $B d$-Brazil and $B d$ GPL isolates. Together, our results demonstrate that functional genomics approaches can provide information relevant to studies of virulence evolution within the $B d$ clade.

Keywords: chytridiomycosis, transcriptomics, fungal pathogenicity, fungal virulence, functional genomics 


\section{INTRODUCTION}

At the height of infectious fungal disease outbreaks, researchers typically place particular focus on understanding the mechanisms that promote hypervirulent lineages. Given the immediacy of effects that virulent outbreaks may have on susceptible host populations, this focus potentially facilitates rapid mitigation. However, critical information can also be gained from examining enzootic pathogens as well as lineages responsible for an epizootic event. Quantifying such intraspecific pathogen variation can help identify the range of pathogenicity mechanisms that result in different disease dynamics in natural populations (Metsky et al., 2017).

One fungal pathogen with widely varying virulence phenotypes is the chytrid fungus, Batrachochytrium dendrobatidis $(B d)$. Highly pathogenic to amphibians, this fungus is globally distributed and responsible for more vertebrate biodiversity loss than any other known wildlife disease (Scheele et al., 2019). First described in 1999, $B d$ has been linked to disease outbreaks in amphibians since the late 1970s (Berger et al., 1998; Fisher et al., 2009b; Longcore et al., 1999).

Initial genetic work suggested that $B d$ was a novel and recently emerged clone, however, successive studies have now uncovered increasing degrees of genetic diversity, pointing to a heterogeneous evolutionary history involving both globally invasive and highly divergent enzootic genotypes with more limited geographic distributions (Bataille et al., 2013; Farrer et al., 2013, 2011; James et al., 2009; Morehouse et al., 2003; O’Hanlon et al., 2018; Rosenblum et al., 2013; Schloegel et al., 2012). There are four such enzootic genotypes within the $B d$ phylogeny, which are geographically restricted to Africa (Bd-Cape), Europe (Bd-Ch), Brazil and Korea ( $B d-$ 
Brazil/Bd-Asia2), and Korea (Bd-Asia1) (Bataille et al., 2013; Farrer et al., 2011;

O'Hanlon et al., 2018; Schloegel et al., 2012). In contrast, the virulent Global Panzootic Lineage ( $B d-G P L)$ diverged only $50-120$ years ago, and is now globally distributed (O’Hanlon et al., 2018).

Of the enzootic $B d$ lineages, $B d$-Brazil offers a good opportunity for comparing enzootic versus epizootic fungal traits. Both $B d$-Brazil and $B d-G P L$ are present in the southern Brazilian Atlantic Forest, which is a biodiversity and endemicity hotspot (Haddad et al., 2013; James et al., 2015; Jenkinson et al., 2016; Myers et al., 2000; Rodriguez et al., 2014). Retrospective analyses of preserved anurans confirm the presence of $B d-G P L$ and $B d$-Brazil in the the region since at least 1894 , with peak prevalence during frog declines in the 1970s and 1980s (Carvalho et al., 2017; Rodriguez et al., 2014). The enzootic Bd-Brazil is more geographically structured than $B d-G P L$, suggesting long-term endemism of the former and recent invasion of the latter (Jenkinson et al., 2016). A leading hypothesis is that the panzootic lineage is outcompeting and replacing enzootic genotypes (James et al., 2015; Jenkinson et al., 2016). However, the functional traits that may be facilitating expansion in Bd-GPL, while restricting it in $B d$-Brazil, are currently unknown.

Functionally, the majority of Chytridiomycota fungi are saprotrophs, and parasitism of adult vertebrate hosts has arisen only once with the genus Batrachochytrium (James et al., 2006; Joneson et al., 2011). Gene family expansions of various peptidase domains within the $B d$ lineage suggest that proteases may be associated with this transition to pathogenicity (Joneson et al., 2011). Beyond a transition to pathogenicity, the relative fitness and virulence of enzootic versus 
panzootic isolates is more complex. $B d$-Brazil does not cause significant mortality in clinical infection trials of Brazilian amphibian hosts, while Bd-GPL does (Becker et al., 2014; Bovo et al., 2016). Lower virulence in Bd-Brazil could be linked to its smaller zoosporangium size. Zoosporangium size has been linked to virulence within the $B d$ clade, wherein larger zoosporangia are thought to lead to greater host epithelial damage and increased zoospore production (Becker et al., 2017; Farrer et al., 2011; James et al., 2009; Lambertini et al., 2016). As with zoosporangium size, membrane composition may play a role in $B d$ pathogenesis. When grown in a live amphibian host compared to in culture, Bd-GPL increases expression of membrane transport activity genes (Ellison et al., 2017). However, isolates of the so-called hypervirulent lineage have significant variation in phenotype and virulence, even at microgeographic scales, and disease outcomes are context-dependent (Berger et al., 2005; Fisher et al., 2009a; Lambertini et al., 2016; O'Hanlon et al., 2018). Given this heterogeneity in both pathogen demography and virulence phenotype, a more complete examination of intraspecific variation between $B d$-Brazil and $B d$-GPL has the potential to distinguish lineage-specific functional differences in a region of high amphibian conservation concern.

To investigate enzootic and panzootic variation between $B d$-Brazil and $B d-G P L$, we compared the gene expression phenotypes of six $B d$ isolates using RNAsequencing. Because $B d$ fitness can vary widely depending on host species, individual host immunity, and environmental conditions, we sought to determine baseline differences in pathogen expression phenotypes between these two lineages by looking at constitutive expression in vitro. Given that the enzootic Brazilian lineage is more 
geographically restricted and potentially outcompeted by $B d-G P L$, we hypothesized that relative to $B d$-Brazil, $B d$-GPL would display increased expression of putative virulence factors including peptidases and transmembrane transporters (Abramyan and Stajich, 2012; Ellison et al., 2017; Joneson et al., 2011; Rosenblum et al., 2013). Based on these expression results, we provide a set of candidate genes that may warrant further study to better understand how genetic variation relates to lineage-specific functional variation relevant to $B d$ pathogenicity.

\section{METHODS}

\subsection{Bd Isolates}

We selected isolates that were obtained from wild hosts between 2004 and 2013 (Table 1). All isolates were cryopreserved shortly after initial recovery to minimize virulence attenuation, which has been demonstrated with long-term $B d$ culture (Langhammer et al., 2013; Refsnider et al., 2015). To standardize growth conditions and ensure that observed gene expression phenotypes were constitutive, we performed in vitro growth assays in nutrient-rich media ( $1 \%$ tryptone, $1 \%$ agar plates) at $21^{\circ} \mathrm{C}$. Each plate was inoculated with $5 \times 10^{6}$ zoospores standardized via hemocytometer. $B d$ isolates vary slightly in growth rate, and harvesting all isolates on the same day may capture slight differences in life stage. To limit gene expression variation due to differences in life stage among replicates, we collected each isolate once peak zoospore motility was observed under light microscopy (between 5 and 6 days, depending on isolate). Although harvesting isolates at peak zoospore motility likely captured proportionally more zoospores than zoosporangia, we did not filter our 
samples to exclude the latter; consequently, the expression profiles captured cannot be

140 linked explicitly to specific life stage. We collected all growth stages, snap-froze them in 141 liquid nitrogen, and stored them at $-80^{\circ} \mathrm{C}$ until RNA isolation.

\subsection{Read Mapping}

\subsection{RNA isolation and sequencing}

We isolated total RNA from three biological replicates of each $B d$ isolate using an RNeasy Mini Kit according to the manufacturer's instructions and including an oncolumn DNase digestion (Qiagen). RNA was eluted in $50 \mu \mathrm{l}$ nuclease-free water and stored at $-80^{\circ} \mathrm{C}$ until library preparation. Libraries for each biological replicate were prepared using the Illumina TruSeq RNA sample preparation kit v2.0 with minor changes to the manufacturer's instructions (Illumina, San Diego). For each replicate, we purified mRNA from total RNA via oligo dT magnetic bead purification and fragmentation $\left(94^{\circ} \mathrm{C}, 6\right.$ minutes). mRNA fragments were then reverse-transcribed into first-strand cDNA with random hexamer primers (Illumina) and SuperScript II Reverse Transcriptase (Invitrogen), and second-strand cDNA was generated with Illumina proprietary consumables. Following end repair, 3' adenylation, and barcoded adapter ligation according to manufacturer protocol, DNA libraries were amplified via 14 PCR cycles. We pooled libraries over two lanes for $100 \mathrm{bp}$, single-end sequencing using Illumina HiSeq in Rapid Run Mode at the Cornell Biotechnology Resource Center Genomics Facility. 
162 Illumina filtering. Read quality was improved using Trimmomatic version 0.36 (Bolger et 163 al. 2014). We removed Illumina adapter sequences and the first 15 base pairs of each 164 read, trimmed 3' and 5' ends if quality score dropped below Q20, trimmed all reads if a 1655 base pair window had a quality score below Q20, and discarded all reads less than 36 166 base pairs long. We confirmed improved quality with FastQC.

We aligned all reads passing quality control to the $B d$ genome (JEL423, assembly GCA_000149865.1) using STAR 2.5.2b (Dobin et al. 2013). We mapped all sequence reads to the index genome with the following additional parameters: spurious and non-canonical unannotated junctions were filtered, and quantMode was used to generate read counts per gene. Raw read counts for each isolate were then compiled for downstream expression analyses.

\subsection{Gene expression analyses}

We performed differential gene expression analyses with edgeR v3.4 (Robinson et al., 2009) implemented in R (version 3.2.0, R Development Core Team 2015). Raw reads were converted to counts per million (cpm) to account for differences in library size. To ensure that our differential expression tests were performed on biologically relevant transcripts and not simply background noise, we used a conservative filtering 180 strategy, retaining only genes with greater than two cpm in at least six libraries, or one $181 \mathrm{cpm}$ in 12 libraries. Filtered raw read counts were then normalized using the trimmed 182 mean of m-values (TMM), which accounts for differences in library composition based 
on the assumption that the majority of genes common among samples are not differentially expressed (Robinson and Oshlack, 2010).

To analyze lineage-specific expression differences, isolates were partitioned into two groups: enzootic (Bd-Brazil; isolates CLFT001 and CLFT044) and panzootic (BdGPL; isolates JEL422, JEL410, CLFT023, CLFT026). Based on expression phenotypes in this initial lineage-based comparison, we then conducted the following pairwise comparisons: $B d$-Brazil vs. $B d$-GPL with JEL422 excluded, $B d$-Brazil vs. JEL422, and JEL422 vs. all other Bd-GPL strains (JEL410, CLFT023, CLFT026). Finally, to quantify expression differences on a finer temporal and geographic scale, we compared pairwise differences between $B d$-GPL isolates JEL410 and JEL422, both of which were originally isolated during the same epizootic event in El Copé, Panama in 2004.

Tests for differential expression were performed with generalized linear model likelihood-ratio tests, and only genes with expression above a log fold change of 1 and an FDR-corrected $P$ value of $<0.05$ were considered significant (Benjamini and Hochberg, 1995). We used a principal components analysis (PCA) to assess sample and biological replicate clustering and visualized global patterns of differential expression between lineages and isolates via heatmaps using normalized, logtransformed z-scores of counts data.

\subsection{Functional annotation and enrichment}

We annotated the $B d$ genome using the National Center for Biotechnology Information (NCBI) non-redundant protein database using Blastp with an E-value of $1 \times 10^{4}$ and up to 20 hits retained. Functional annotation to identify homologous Gene 
Ontology (GO) terms for each protein was performed using Blast2GO Command Line

v1.2.1 (www.blast2go.com), retaining annotations with an E-value of $1 \times 10^{6}$, a GO set.

weight of 5 , and a minimum cut off of 55 . To identify functional enrichment, we performed Fisher's exact tests in Blast2GO to identify significantly overrepresented processes in each treatment group relative to the reference gene set, the annotated JEL423 Bd genome. We then used the web-based tool, Revigo, to remove redundant GO terms, retaining terms with a similarity score of 0.7 or less (Supek et al. 2011). We plotted results as histograms depicting the percentage of genes with enrichment in the test set of significantly differentially expressed genes relative to the JEL423 reference

\subsection{Data Availability}

All sequence data are available in the NCBI Short Read Archive, BioProject number PRJNA400613. File S1 contains the GO annotation file (generated by Blast2GO) used in functional enrichment tests. File S2 contains all differential gene expression test data. File S3 contains further metadata of the differentially expressed genes discussed.

\section{RESULTS}

\subsection{Mapping and annotation}

We recovered over 379 million raw reads at an average of 21 million reads per sample. Of these, we retained an average of 19.2 million reads per sample following filtering. Filtered reads aligned to the JEL423 reference genome at an alignment rate of 90.09-92.88\% uniquely mapped reads (Table S1). Because the reference genome is 
derived from a $B d$-GPL isolate, genes unique to the $B d$-Brazil lineage are not captured in this analysis. However, mapping rates across all isolates and lineages were above $90 \%$, indicating that any discrepancy is likely to be minor. Principal components analysis revealed that our samples clustered by isolate and by lineage, with no apparent outliers (Figure 1). At an E-value cutoff of $1 \times 10^{6}$, we functionally annotated $6,860(69 \%)$ of the 9,879 JEL423 reference genes (File S1).

\subsection{Enzootic vs. panzootic gene expression}

To determine lineage-specific differences in expression phenotype, we first partitioned our samples according to membership in the enzootic versus panzootic lineages. Specifically, we compared expression patterns between Bd-Brazil (CLFT001 and CLFT044) and Bd-GPL (CLFT023, CLFT026, CLFT410, CLFT422) to find a total of 509 genes with significant lineage-specific differential expression (Figure 2). We focused our analysis on genes thought to be involved in $B d$ pathogenesis, specifically carbohydrate-binding module 18 (CBM18) chitin-binding genes, M36 metalloproteases, as well as those associated with reactive oxygen metabolism and peptidase activity (Farrer et al., 2017; Joneson et al., 2011; Rosenblum et al., 2013).

Of these, we found that superoxide dismutase, glutathione S-transferase, CBM18 genes, as well as genes with aspartic-type, serine-type, and M36-domain protease activity were among the most differentially expressed between lineages (Figure 3). Of

249 the 16 genes with aspartic-type peptidase activity that were significantly differentially 250 expressed between $B d$-Brazil and $B d$-GPL, 10 were overexpressed in $B d$-Brazil (Figure 
more varied expression both within and between the enzootic and panzootic lineages

(Figure 3 ). Three superoxide dismutase genes were significantly differentially expressed, with two increased in Bd-Brazil. Conversely, Bd-GPL overexpressed glutathione S-transferase and all significant CBM18 genes.

We confirmed an overall increase in expression of peptidase genes in the $B d-$ Brazil lineage via functional enrichment tests. We found enrichment for GO terms associated with peptidase activity, as well as more general terms involving biological and metabolic activity (e.g. cytosol, cell communication, cell death; Figure S2a).

Conversely, genes with increased expression in Bd-GPL were significantly enriched for GO terms linked to membrane composition (Figure S2a).

\subsection{Expression patterns further partitioned}

Our principal components analysis revealed that our samples clustered into three groups along the first axis: $B d$-Brazil, a main $B d$-GPL group, and isolate JEL422 as an outlier from the main Bd-GPL cluster (Figure 1). Thus, we further partitioned our analysis between these three groups to detect more fine-scale expression differences. When comparing expression between $B d$-Brazil and $B d-G P L$ without isolate JEL422, 321 genes were significantly differentially expressed. Genes upregulated in $B d$-Brazil showed a similar pattern to our original analysis; all superoxide dismutase, glutathione S-transferase, CBM18, and peptidase activity genes significantly differentially expressed between $B d$-Brazil and $B d$-GPL without JEL422 were also differentially expressed between $B d$-Brazil and Bd-GPL overall (Figure 3). With JEL422 removed, we again found enrichment for peptidase activity and biological and metabolic processes in 
genes upregulated by $B d$-Brazil, however there was no longer enrichment for membrane composition among genes upregulated by $B d-G P L$ (Figure S2b).

In contrast, pairwise comparisons of JEL422 to $B d$-Brazil and to the remaining $B d-G P L$ isolates revealed that the Panamanian epizootic isolate exhibited enrichment for membrane composition and transmembrane transport genes, as well as those involved in ciliary structure and function (Figure S3). Genes related to membrane composition, transmembrane transport, and ciliary structure consistently showed the highest expression in JEL422 relative to other Bd-GPL isolates (Figure 4). While transmembrane transport and membrane composition genes were also significantly increased in JEL422 compared to Bd-Brazil, ciliary genes were not significantly differentially expressed between these two groups. Instead, expression levels between JEL422 and the Bd-Brazil isolate, CLFT001, were similar overall (Figure 4).

Thus, $B d$-Brazil increases expression of aspartic-type peptidase activity and CBM18 genes relative to all $B d$-GPL isolates in this study, including JEL422. In contrast, JEL422 is unique among our $B d$-GPL isolates in its increased expression related to membrane composition and transmembrane transport.

\subsection{Expression and sympatry}

Because JEL422 and JEL410 were both isolated at the same time and location during the El Copé epizootic (Table 1), and previous studies including El Copé isolates have found little genomic variation among them (James et al., 2009; Rosenblum et al., 2013), we predicted that gene expression patterns would be similar between these two isolates. Instead, we found that expression patterns were highly divergent, and that 
JEL410 samples clustered more closely with Brazilian Bd-GPL isolates than with JEL422 (Figure 1, Figure 2). A comparison of expression between JEL410 and JEL422 revealed that 3,503 genes-more than one third of all $B d$ genes—were significantly differentially expressed. As with our examination of Brazilian Bd-GPL isolates, JEL410 is enriched for metabolic and biosynthetic processes (Figure S4). In contrast, compared to JEL410, JEL422 increased expression of membrane, transmembrane transport, and ciliary genes (Figure 4, Figure S4).

\section{DISCUSSION}

The $B d$ lineage is genetically and functionally diverse, with several enzootic lineages and one panzootic lineage that is disproportionately responsible for amphibian declines (O'Hanlon et al., 2018). Given the prevailing hypothesis that the panzootic BdGPL is outcompeting enzootic lineages, we analyzed overall patterns of gene expression between $B d-G P L$ and one enzootic lineage ( $B d$-Brazil) to identify functional genomic differences that may be related to this competitive success. We focus on this lineage comparison because $B d$-Brazil and $B d-G P L$ are sympatric in a region of high pathogen and host diversity in the Americas (Scheele et al., 2019). Examining their expression phenotypes is thus informative as we continue to monitor the effects of this pathogen in the Brazilian Atlantic Forest.

As expected given its early divergence in the $B d$ lineage, we found that global gene expression of the enzootic $B d$-Brazil was significantly different from that of the more recently evolved $B d-G P L$. Gene expression variation could be undetectable due to the deep genetic divergence between these two lineages (O'Hanlon et al., 2018). 
However, despite this divergence, the variation demonstrated in our study indicates a level of constitutive lineage-specific expression among the core set of annotated $B d$ genes. Among the most highly differentially expressed genes between $B d$-Brazil and $B d-G P L$, we found that superoxide dismutase and genes enriched for aspartic-type peptidase activity were generally increased in $B d$-Brazil, while glutathione S-transferase and CBM18 chitin-binding genes were decreased. M36 metalloproteases and genes enriched for serine-type peptidase activity showed more variable expression both within and between lineages.

Among genes significantly increased in $B d$-Brazil, we found enrichment generally for those related to peptidase activity, and those with aspartic-type peptidase activity in particular had some of the highest expression levels compared to Bd-GPL (Figure 3, Figure S1, Figure S2). Peptidases have been implicated in allowing for the evolutionary transition to pathogenicity in $B d$, and the $B d$ genome has expansions of aspartyl protease, M36 metalloprotease, and serine-type protease gene families compared to its closest chytrid relative (Joneson et al., 2011). Peptidases are virulence factors in other fungal pathogens, most notably Candida and Aspergillus species, and aspartic-type peptidases in particular play a role in fungal metabolism and host interaction (Brutyn et al., 2012; Monod et al., 2002; Palmeira et al., 2017; Santos, 2011). Our finding of a trend toward increased aspartic-type peptidase expression in the enzootic lineage may support the hypothesis that peptidase genes have allowed $B d$ to exploit vertebrate protein as a viable substrate, and thus aid its evolution toward pathogenicity. Because 
enrichment for aspartic-type peptidase activity, the relative importance of these enzymes in facilitating the global spread of $B d-G P L$ is unclear.

Compared to genes with aspartic-type peptidase activity, M36 metalloproteases and genes associated with serine-type peptidase activity showed more variable expression. M36 proteases were highly expressed by Bd-Brazil isolate CLFT001, while expression in CLFT044 was comparable to the Bd-GPL lineage. Similarly, serine-type peptidase activity genes were both upregulated and downregulated in $B d$-Brazil compared to $B d$-GPL (Figure 3). Previous studies have found that when grown in a live amphibian host or in tissue-inoculated media compared to in culture, secreted proteases are upregulated (Farrer et al., 2017; Rosenblum et al., 2012). The variable expression in M36 metalloprotease and serine-type peptidase genes demonstrates more complexity in intra- and inter-lineage-specific constitutive protease expression. Comparing the activity of protease orthologs expressed by each lineage and isolate through functional studies will be necessary to fully understand the role of these enzymes across $B d$-Brazil and $B d$-GPL lineages.

In addition to peptidases, we found that CBM18 genes were some of the most significantly differentially expressed between $B d$-Brazil and Bd-GPL (Figure 3). CBM18 genes are putative virulence factors in $B d$ because they are notably expanded in the $B d$ clade compared to its closest saprobic fungal relative (Abramyan and Stajich, 2012).

Though they are predicted to bind chitin, their function in $B d$ is under active investigation. A recent study found that they are unresponsive to host chitinase, suggesting that rather than a direct protective capacity, they may instead be involved in decreasing host chitin recognition response, or in adhesion to the host skin (Farrer et 
al., 2017). Of the three CBM18 genes that were significantly differentially expressed

367

368

369

370

371

372

373

374

375

376

377

378

379

380

381

382

383

384

385

386

387

388

between $B d$-Brazil and $B d-G P L$, all were upregulated in the panzootic lineage. This consistent overexpression in the globally invasive $B d$-GPL may lend further support to the hypothesis that CBM18 genes are key pathogenicity factors in the lineage.

We found that among annotated $B d$ genes, some of those with the greatest magnitude of expression change between the two lineages were involved in detoxification. Relative to $B d$-Brazil, $B d$-GPL isolates increased expression of glutathione S-transferase (Figure 3). Glutathione S-transferases (GSTs) are highly conserved detoxification enzymes with postulated roles in tolerance of host defense compounds (Choi et al., 1998; Morel et al., 2009; Prins et al., 2000; Veal et al., 2002). In addition to GST, superoxide dismutase genes were also significantly differentially expressed between lineages. Fungal superoxide dismutases (SODs) are similarly involved in stress tolerance, and contribute to both pathogenesis and virulence in fungi through detoxification of reactive oxygen compounds (Cox et al., 2003; Xie et al., 2010; Youseff et al., 2012). With respect to $B d$, a previous study found that loss of heterozygosity $(\mathrm{LOH})$ blocks in the $B d$ genome were enriched for genes related to superoxide dismutase activity, suggesting that these genes may be under selection (Rosenblum et al., 2013).

Our results demonstrate that glutathione S-transferase and superoxide dismutases are highly differentially expressed between lineages. While two of the three significant SODs are overexpressed in Bd-Brazil, the third SOD and only significant GST show an inverse pattern of expression, with increases in Bd-GPL instead. Thus, constitutive expression of detoxification enzymes appears to vary by gene with no clear 
lineage-specific pattern across gene class, and further functional studies will help to clarify the extent of their importance to particular $B d$ lineages. Moreover, examining the life stage-specific expression of these enzymes will help delineate whether they play a role in host colonization and immune evasion.

When all four panzootic isolates were included in our analysis, the $B d-G P L$ lineage exhibited increased expression of genes enriched for membrane composition (Figure S2a). Upon further examination, it is clear that the JEL422 isolate alone is driving this expression phenotype (Figure 4, Figure S2, Figure S3, Figure S4). In comparisons of JEL422 to either Bd-Brazil or to the other Bd-GPL isolates, the former still demonstrates increased expression of and enrichment for membrane-related genes, as well genes involved in transmembrane transport (Figure 4).

The current study was performed in vitro to control for variation in growth conditions and thus does not capture $B d$ expression in response to its native environment. However, previous studies involving highly virulent $B d-G P L$ isolates in vivo also find increased expression of membrane function genes. $B d$ is known to secrete lymphotoxic inhibitory factors (Fites et al., 2013), and specific changes in membrane composition may facilitate this secretory ability. The importance of membrane composition has been observed in the highly virulent $B d-G P L$ isolate, JEL423, which upregulates expression of multiple transmembrane transporters when grown in live frogs versus in culture (Ellison et al., 2017). Fungal evasion of host immune response and resistance to antifungal agents is well-documented, and is often made possible by alterations to the cell wall and membrane (Behnsen et al., 2008; Kanafani and Perfect, 2008; Luo et al., 2013). Moreover, transmembrane transporters may provide protection 
against host antimicrobial compounds via secretion of host-directed toxins

413 (Stergiopoulos et al. 2002).

We found consistent overexpression of membrane and transmembrane transport genes in JEL422 compared to other isolates. Unfortunately, we have no virulence estimates for this isolate, although it was obtained during an active epizootic outbreak in Panama, and is thus presumed to be highly virulent. Understanding the biological relevance of this constitutive expression in JEL422 requires further investigation of its in vivo virulence. The consistency of JEL422 upregulation across multiple membrane and transmembrane transport genes is remarkable, and warrants further study to determine the importance of this isolate-specific expression phenotype.

In addition to membrane composition and transmembrane transporter activity, relative to all other $B d$-GPL strains, JEL422 also showed increased expression of genes associated with ciliary structure and function (Figure 4). When grown in a live host, $B d$ increases expression of genes enriched for cilium morphogenesis (Ellison et al., 2017). Moreover, increased zoospore production and dispersal ability may be a potential avenue by which $B d$ isolates increase host access and infection intensity (DiRenzo et al. 2014; Piotrowski et al. 2004). Because we harvested all isolates at their point of peak zoospore density and motility, upregulation of ciliary genes is unlikely to be an artifact of life stage differences among our isolates.

While JEL422 ciliary gene expression was significantly higher than other Bd-GPL 432 isolates, it was comparable to that of $B d$-Brazil isolate CLFT001 (Figure 4). Without 433 comprehensive data on zoospore morphology and motility for each isolate, we cannot 
constitutive expression of ciliary genes in these two isolates may warrant further study to understand how this expression relates to isolate-specific dispersal ability.

Our results demonstrate that constitutive gene expression in $B d$ varies significantly both between and within Bd-Brazil and Bd-GPL lineages. Although both of the Panamanian isolates we used were obtained during an active epizootic event in El Copé, Panama, and were thus presumed to be highly virulent, JEL410 and JEL422 exhibit divergent expression phenotypes (Figure 1). JEL422 was isolated from a highly susceptible host species, Sachatamia albomaculata, whereas JEL410 was cultured from the putatively resistant Pristimantis muscosus (Table 1). Though the pathogenesis of both of our Panamanian isolates has not been experimentally confirmed, the divergent expression patterns we observed in two presumptively clonal, sympatric isolates adds to previous observations of extensive functional and phenotypic variation in the $B d$ clade at a fine geographic scale (Jenkinson et al., 2016; Lambertini et al., 2016). A greater understanding of microgeographic and host-specific in vivo functional differences may refine our knowledge of $B d$ disease dynamics.

Our sample size is limited to six isolates, and thus our results serve as a preliminary analysis of $B d$ gene expression in Bd-Brazil compared to Bd-GPL.

Subsequent studies that include additional isolates will improve resolution and power. In particular, comparing gene expression phenotypes in the other three enzootic lineages will more comprehensively clarify functional genomic differences across the clade. While profiling large numbers of isolates in vivo is logistically difficult, analyzing $B d$ transcriptional responses in a more realistic host proxy system will also be valuable in 
relating the gene expression phenotypes we observe to direct measures of pathogenicity and virulence.

RNAseq is an accessible approach to genomic studies in non-model systems, further test hypotheses of $B d$ pathogenesis.

\section{CONCLUSIONS}

$B d$ is a global pathogen with deep phylogenetic structure (Farrer et al., 2011; Jenkinson et al., 2016; Rosenblum et al., 2013) and broad variation in pathogenicity (Becker et al., 2017; Berger et al., 2005; Fisher et al., 2009a; Voyles et al., 2018).

479 Identifying the genomic elements encoding these differences in virulence phenotypes 
remains a central question in this and most other host-pathogen systems. Previous genomic studies have identified various proteolytic gene family expansions and other signatures of selection in genes suggested to confer virulence to $B d$ (Abramyan and Stajich, 2012; Joneson et al., 2011; Rosenblum et al., 2012, 2008). Our results provide

a remarkable confirmation of the importance of genes involved in proteolysis, and the overexpression of aspartic-type peptidase related genes in the more ancestral, enzootic $B d$-Brazil lineage supports the hypothesis that proteolytic ability allowed for the transition from saprotroph to vertebrate pathogen. We also demonstrate that expression phenotype varies significantly within the recently diverged panzootic $B d$-GPL lineage, and that variation in cell membrane and transmembrane transport gene expression within isolate JEL422 is particularly pronounced. While gene expression does not definitively confirm function, the ability to quantify gene production renders such transcriptome-based analyses integral in determining the biological significance of molecular variation in fungal pathogens.

\section{ACKNOWLEDGEMENTS}

The authors thank Joyce Longcore for providing the $B d$ isolates used in this study, Miranda Gray for assistance in the laboratory, Ezra Lencer for feedback on methods, the Cornell Biotechnology Resource Center for sequencing and bioinformatics troubleshooting, and Zamudio lab members for helpful manuscript comments. This work was funded by the National Science Foundation (NSF grant DEB 1120249) and the Cornell Center for Vertebrate Genomics. 


\section{REFERENCES}

504 Abramyan, J., Stajich, J.E., 2012. Species-specific chitin-binding module 18 expansion

in the amphibian pathogen Batrachochytrium dendrobatidis. MBio 3, 1-9. https://doi.org/10.1128/mBio.00150-12

Bataille, A., Fong, J.J., Cha, M., Wogan, G.O.U., Baek, H.J., Lee, H., Min, M.-S., Waldman, B., 2013. Genetic evidence for a high diversity and wide distribution of endemic strains of the pathogenic chytrid fungus Batrachochytrium dendrobatidis in wild Asian amphibians. Mol. Ecol. 22, 4196-4209. https://doi.org/10.1111/mec.12385

Becker, C.G., Greenspan, S.E., Tracy, K.E., Dash, J.A., Lambertini, C., Jenkinson, T.S., Leite, D.S., Toledo, L.F., Longcore, J.E., James, T.Y., Zamudio, K.R., 2017. Variation in phenotype and virulence among enzootic and panzootic amphibian chytrid lineages. Fungal Ecol. 26, 45-50.

https://doi.org/10.1016/j.funeco.2016.11.007

Becker, C.G., Rodriguez, D., Toledo, L.F., Longo, A. V, Lambertini, C., Corrêa, D.T., Leite, D.S., Haddad, C.F.B., Zamudio, K.R., 2014. Partitioning the net effect of host diversity on an emerging amphibian pathogen. Proc. Biol. Sci. 281, 1-7. https://doi.org/10.1098/rspb.2014.1796

Behnsen, J., Hartmann, A., Schmaler, J., Gehrke, A., Brakhage, A.A., Zipfel, P.F., 2008. The opportunistic human pathogenic fungus Aspergillus fumigatus evades the host complement system. Infect. Immun. 76, 820-827. https://doi.org/10.1128/IAI.01037-07

Benjamini, Y., Hochberg, Y., 1995. Controlling the False Discovery Rate: A Practical 
and Powerful Approach to Multiple Testing. J. R. Stat. Soc. Ser. B 57, 289-300. https://doi.org/10.1111/j.2517-6161.1995.tb02031.x

Berger, L., Marantelli, G., Skerratt, L.F., Speare, R., 2005. Virulence of the amphibian chytrid fungus Batrachochytium dendrobatidis varies with the strain. Dis. Aquat. Organ. 68, 47-50. https://doi.org/10.3354/dao068047

Berger, L., Speare, R., Daszak, P., Green, D.E., Cunningham, A.A., Goggin, C.L., Slocombe, R., Ragan, M.A., Hyatt, A.D., McDonald, K.R., Hines, H.B., Lips, K.R., Marantelli, G., Parkes, H., 1998. Chytridiomycosis causes amphibian mortality associated with population declines in the rain forests of Australia and Central America. Proc. Natl. Acad. Sci. 95, 9031-9036.

Bolger, A.M., Lohse, M., Usadel, B., 2014. Trimmomatic: a flexible trimmer for Illumina sequence data. Bioinformatics 30, 2114-2120. https://doi.org/10.1093/bioinformatics/btu170

Bovo, R.P., Andrade, D. V., Toledo, L.F., Longo, A. V., Rodriguez, D., Haddad, C.F.B., Zamudio, K.R., Becker, C.G., 2016. Physiological responses of Brazilian amphibians to an enzootic infection of the chytrid fungus Batrachochytrium dendrobatidis. Dis. Aquat. Organ. 117, 245-252. https://doi.org/10.3354/dao02940

Brutyn, M., D’Herde, K., Dhaenens, M., Rooij, P. Van, Verbrugghe, E., Hyatt, A.D., Croubels, S., Deforce, D., Ducatelle, R., Haesebrouck, F., Martel, A., Pasmans, F., 2012. Batrachochytrium dendrobatidis zoospore secretions rapidly disturb intercellular junctions in frog skin. Fungal Genet. Biol. 49, 830-837. https://doi.org/10.1016/j.fgb.2012.07.002

Carvalho, T., Becker, C.G., Toledo, L.F., 2017. Historical amphibian declines and 
extinctions in Brazil linked to chytridiomycosis. Proc. R. Soc. B Biol. Sci. 284, 20162254. https://doi.org/10.1098/rspb.2016.2254

Choi, J.H., Lou, W., Vancura, A., 1998. A ovel membrane-bound glutathione S-

transferase functions in the stationary phase of the yeast Saccharomyces cerevisiae. J. Biol. Chem. 273, 29915-29922.

https://doi.org/10.1074/jbc.273.45.29915

Cox, G.M., Harrison, T.S., McDade, H.C., Taborda, C.P., Heinrich, G., Casadevall, A., Perfect, J.R., 2003. Superoxide dismutase influences the virulence of Cryptococcus neoformans by affecting growth within macrophages. Infect. Immun. 71, 173-180. https://doi.org/10.1128/IAI.71.1.173-180.2003

DiRenzo, G. V, Langhammer, P.F., Zamudio, K.R., Lips, K.R., 2014. Fungal infection intensity and zoospore output of Atelopus zeteki, a potential acute chytrid supershedder. PLoS One 9, e93356. https://doi.org/10.1371/journal.pone.0093356

Dobin, A., Davis, C.A., Schlesinger, F., Drenkow, J., Zaleski, C., Jha, S., Batut, P., Chaisson, M., Gingeras, T.R., 2013. STAR: ultrafast universal RNA-seq aligner. Bioinformatics 29, 15-21. https://doi.org/doi: 10.1093/bioinformatics/bts635

Ellison, A.R., DiRenzo, G., McDonald, C.A., Lips, K.R., Zamudio, K.R., 2017. First in vivo Batrachochytrium dendrobatidis transcriptomes reveal mechanisms of host exploitation, host-specific gene expression, and expressed genotype shifts. G3 Genes|Genomes|Genetics 7, 269-278. https://doi.org/10.1534/g3.116.035873

Ellison, A.R., Savage, A.E., DiRenzo, G. V, Langhammer, P., Lips, K.R., Zamudio, K.R., 2014a. Fighting a losing battle: vigorous immune response countered by pathogen suppression of host defenses in the chytridiomycosis-susceptible frog Atelopus 
zeteki. G3 Genes|Genomes|Genetics 4, 1275-1289. https://doi.org/10.1534/g3.114.010744

Ellison, A.R., Tunstall, T., DiRenzo, G. V, Hughey, M.C., Rebollar, E.A., Belden, L.K., Harris, R.N., Ibáñez, R., Lips, K.R., Zamudio, K.R., 2014b. More than skin deep: functional genomic basis for resistance to amphibian chytridiomycosis. Genome Biol. Evol. 7, 286-298. https://doi.org/10.1093/gbe/evu285

Farrer, R.A., Henk, D.A., Garner, T.W.J., Balloux, F., Woodhams, D.C., Fisher, M.C., 2013. Chromosomal copy number variation, selection and uneven rates of recombination reveal cryptic genome diversity linked to pathogenicity. PLoS Genet. 9, e1003703. https://doi.org/10.1371/journal.pgen.1003703

Farrer, R.A., Martel, A., Verbrugghe, E., Abouelleil, A., Ducatelle, R., Longcore, J.E., James, T.Y., Pasmans, F., Fisher, M.C., Cuomo, C.A., 2017. Genomic innovations linked to infection strategies across emerging pathogenic chytrid fungi. Nat. Commun. 8, 1-11. https://doi.org/10.1038/ncomms14742

Farrer, R.A., Weinert, L.A., Bielby, J., Garner, T.W.J., Balloux, F., Clare, F., Bosch, J., Cunningham, A.A., Weldon, C., Louis, H., Anderson, L., Kosakovsky, S.L., Shahargolan, R., Henk, D.A., Fisher, M.C., 2011. Multiple emergences of genetically diverse amphibian-infecting chytrids include a globalized hypervirulent recombinant lineage. Proc. Natl. Acad. Sci. 108, 18732-18736.

https://doi.org/10.1073/pnas.1111915108/-

/DCSupplemental.www.pnas.org/cgi/doi/10.1073/pnas.1111915108

Fisher, M.C., Bosch, J., Yin, Z., Stead, D.A., Walker, J., Selway, L., Brown, A.J.P., Walker, L.A., Gow, N.A.R., Stajich, J.E., Garner, T.W.J., 2009a. Proteomic and 
phenotypic profiling of the amphibian pathogen Batrachochytrium dendrobatidis

James, T.Y., Letcher, P.M., Longcore, J.E., Mozley-Standridge, S.E., Porter, D., Powell,

Fites, J.S., Ramsey, J.P., Whitney, M.H., Collier, S.P., Sutherland, D.M., Reinert, L.K., Gayek, A.S., Dermody, T.S., Aune, T.M., Oswald-Richter, K., Rollins-Smith, L.A., 2013. The invasive chytrid fungus of amphibians paralyzes lymphocyte responses. Science 342, 366-369. https://doi.org/10.5061/dryad.878m3

Haddad, C.F.B., Toledo, L.F., Prado, C.P.A., Loebmann, D., Gasparini, J.L., Sazima, I., 2013. Guide to the amphibians of the Atlantic Forest: diversity and biology. Anolis Books, Sao Paulo.

M.J., Griffith, G.W., Vilgalys, R., 2006. A molecular phylogeny of the flagellated fungi (Chytridiomycota) and description of a new phylum (Blastocladiomycota). Mycologia 98, 860-871.

James, T.Y., Litvintseva, A.P., Vilgalys, R., Morgan, J. a T., Taylor, J.W., Fisher, M.C., Berger, L., Weldon, C., Du Preez, L., Longcore, J.E., 2009. Rapid global expansion of the fungal disease chytridiomycosis into declining and healthy amphibian populations. PLoS Pathog. 5, e1000458.

https://doi.org/10.1371/journal.ppat.1000458 
James, T.Y., Toledo, L.F., Rödder, D., da Silva Leite, D., Belasen, A.M., BetancourtRomán, C.M., Jenkinson, T.S., Lambertini, C., Longo, A. V., Ruggeri, J., Collins, J.P., Burrowes, P. a., Lips, K.R., Zamudio, K.R., Longcore, J.E., 2015.

Disentangling host, pathogen, and environmental determinants of a recently emerged wildlife disease: lessons from the first 15 years of amphibian chytridiomycosis research. Ecol. Evol. 5, 4079-4097. https://doi.org/10.1002/ece3.1672

Jenkinson, T.S., Betancourt Roman, C.M., Lambertini, C., Valencia-Aguilar, A., Rodriguez, D., Nunes-De-Almeida, C.H.L., Ruggeri, J., Belasen, A.M., Da Silva Leite, D., Zamudio, K.R., Longcore, J.E., Toledo, L.F., James, T.Y., 2016. Amphibian-killing chytrid in Brazil comprises both locally endemic and globally expanding populations. Mol. Ecol. 25, 2978-2996. https://doi.org/10.1111/mec.13599

Joneson, S., Stajich, J.E., Shiu, S.H., Rosenblum, E.B., 2011. Genomic transition to pathogenicity in chytrid fungi. PLoS Pathog. 7, e1002338. https://doi.org/10.1371/journal.ppat.1002338

Kanafani, Z.A., Perfect, J.R., 2008. Resistance to antifungal agents: mechanisms and clinical Impact. Clin. Infect. Dis. 46, 120-128. https://doi.org/10.1086/524071

Lambertini, C., Becker, C.G., Jenkinson, T.S., Rodriguez, D., Leite, S., James, T.Y., Zamudio, K.R., Felipe, L., 2016. Local phenotypic variation in amphibian-killing fungus predicts infection dynamics. Fungal Ecol. 20, 15-21. https://doi.org/10.1016/j.funeco.2015.09.014

Langhammer, P.F., Lips, K.R., Burrowes, P. a., Tunstall, T., Palmer, C.M., Collins, J.P., 
2013. A fungal pathogen of amphibians, Batrachochytrium dendrobatidis,

attenuates in pathogenicity with in vitro passages. PLoS One 8, e77630. https://doi.org/10.1371/journal.pone.0077630

Longcore, J.E., Pessier, A.P., Nichols, D.K., 1999. Batrachochytrium dendrobatidis gen. et sp. nov., a chytrid pathogenic to amphibians. Mycologia 91, 219-227.

Luo, S., Skerka, C., Kurzai, O., Zipfel, P.F., 2013. Complement and innate immune evasion strategies of the human pathogenic fungus Candida albicans. Mol. Immunol. 56, 161-169. https://doi.org/10.1016/j.molimm.2013.05.218

Metsky, H.C., Matranga, C.B., Wohl, S., Schaffner, S.F., Freije, C.A., Winnicki, S.M., West, K., Qu, J., Baniecki, M.L., Gladden-Young, A., Lin, A.E., Tomkins-Tinch, C.H., Ye, S.H., Park, D.J., Luo, C.Y., Barnes, K.G., Shah, R.R., Chak, B., BarbosaLima, G., Delatorre, E., Vieira, Y.R., Paul, L.M., Tan, A.L., Barcellona, C.M., Porcelli, M.C., Vasquez, C., Cannons, A.C., Cone, M.R., Hogan, K.N., Kopp, E.W., Anzinger, J.J., Garcia, K.F., Parham, L.A., Ramírez, R.M.G., Montoya, M.C.M., Rojas, D.P., Brown, C.M., Hennigan, S., Sabina, B., Scotland, S., Gangavarapu, K., Grubaugh, N.D., Oliveira, G., Robles-Sikisaka, R., Rambaut, A., Gehrke, L., Smole, S., Halloran, M.E., Villar, L., Mattar, S., Lorenzana, I., Cerbino-Neto, J., Valim, C., Degrave, W., Bozza, P.T., Gnirke, A., Andersen, K.G., Isern, S., Michael, S.F., Bozza, F.A., Souza, T.M.L., Bosch, I., Yozwiak, N.L., Maclnnis, B.L., Sabeti, P.C., 2017. Zika virus evolution and spread in the Americas. Nature 546, 411-415. https://doi.org/10.1038/nature22402

Monod, M., Capoccia, S., Lechenne, B., Zaugg, C., Holdom, M., Jousson, O., 2002. Secreted proteases from pathogenic fungi. Int. J. Med. Microbiol 292, 405-419. 
Morehouse, E.A., James, T.Y., Ganley, A.R.D., Vilgalys, R., Berger, L., Murphy, P.J., Longcore, J.E., 2003. Multilocus sequence typing suggests the chytrid pathogen of amphibians is a recently emerged clone. Mol. Ecol. 12, 395-403.

Morel, M., Ngadin, A.A., Droux, M., Jacquot, J.-P., Gelhaye, E., 2009. The fungal glutathione S-transferase system. Evidence of new classes in the wood-degrading basidiomycete Phanerochaete chrysosporium. Cell. Mol. Life Sci. 66, 3711-3725. https://doi.org/10.1007/s00018-009-0104-5

Myers, N., Mittermeier, R.A., Mittermeier, C.G., da Fonseca, G.A.B., Kent, J., 2000. Biodiversity hotspots for conservation priorities. Nature 403, 853-858. https://doi.org/10.1038/35002501

O'Hanlon, S.J., Rieux, A., Farrer, R.A., Rosa, G.M., Waldman, B., Bataille, A., Kosch, T.A., Murray, K.A., Brankovics, B., Fumagalli, M., Martin, M.D., Wales, N., Alvarado-Rybak, M., Bates, K.A., Berger, L., Böll, S., Brookes, L., Clare, F., Courtois, E.A., Cunningham, A.A., Doherty-Bone, T.M., Ghosh, P., Gower, D.J., Hintz, W.E., Höglund, J., Jenkinson, T.S., Lin, C.-F., Laurila, A., Loyau, A., Martel, A., Meurling, S., Miaud, C., Minting, P., Pasmans, F., Schmeller, D.S., Schmidt, B.R., Shelton, J.M.G., Skerratt, L.F., Smith, F., Soto-Azat, C., Spagnoletti, M., Tessa, G., Toledo, L.F., Valenzuela-Sánchez, A., Verster, R., Vörös, J., Webb, R.J., Wierzbicki, C., Wombwell, E., Zamudio, K.R., Aanensen, D.M., James, T.Y., Gilbert, M.T.P., Weldon, C., Bosch, J., Balloux, F., Garner, T.W.J., Fisher, M.C., 2018. Recent Asian origin of chytrid fungi causing global amphibian declines. Science 360, 621-627. https://doi.org/10.1126/science.aar1965

Palmeira, V.F., Alviano, D.S., Braga-Silva, L.A., Goulart, F.R. V, Granato, M.Q., 
Rozental, S., Alviano, C.S., Santos, A.L.S., Kneipp, L.F., 2017. HIV Aspartic Peptidase Inhibitors Modulate Surface Molecules and Enzyme Activities Involved with Physiopathological Events in Fonsecaea pedrosoi. Front. Microbiol. 8, 1-12. https://doi.org/10.3389/fmicb.2017.00918

Piotrowski, J.S., Annis, S.L., Longcore, J.E., 2004. Physiology of Batrachochytrium dendrobatidis, a chytrid pathogen of amphibians. Mycol. Soc. Am. 96, 9-15.

Prins, T.W., Wagemakers, L., Schouten, A., van Kan, J.A.L., 2000. Cloning and characterization of a glutathione S-transferase homologue from the plant pathogenic fungus Botrytis cinerea. Mol. Plant Pathol. 1, 169-178. https://doi.org/10.1046/j.1364-3703.2000.00021.x

Refsnider, J.M., Poorten, T.J., Langhammer, P.F., Burrowes, P.A., Rosenblum, E.B., 2015. Genomic correlates of virulence attenuation in the deadly amphibian chytrid fungus, Batrachochytrium dendrobatidis. G3 Genes|Genomes|Genetics 5, 22912298. https://doi.org/10.1534/g3.115.021808

Robinson, M.D., McCarthy, D.J., Smyth, G.K., 2009. edgeR: a bioconductor package for differential expression analysis of digital gene expression data. Bioinformatics 26, 139-140. https://doi.org/10.1093/bioinformatics/btp616

Robinson, M.D., Oshlack, A., 2010. A scaling normalization method for differential expression analysis of RNA-seq data 11, 1-9. https://doi.org/10.1186/gb-2010-11$3-r 25$

Rodriguez, D., Becker, C.G., Pupin, N.C., Haddad, C.F.B., Zamudio, K.R., 2014. Longterm endemism of two highly divergent lineages of the amphibian-killing fungus in the Atlantic Forest of Brazil. Mol. Ecol. 23, 774-787. 
https://doi.org/10.1111/mec.12615

Rosenblum, E.B., James, T.Y., Zamudio, K.R., Poorten, T.J., Ilut, D., Rodriguez, D., Parra Olea, G., Toledo, L.F., Arellano, M.L., Medina, E.M., Restrepo, S., Flechas, S.V., Berger, L., Briggs, C.J., Stajich, J.E., 2013. Complex history of the amphibiankilling chytrid fungus revealed with genome resequencing data. Proc. Natl. Acad. Sci. U. S. A. 110, 9385-9390. https://doi.org/10.1073/pnas.1300130110

Rosenblum, E.B., Poorten, T.J., Joneson, S., Settles, M., 2012. Substrate-specific gene expression in Batrachochytrium dendrobatidis, the chytrid pathogen of amphibians. PLoS One 7, e49924. https://doi.org/10.1371/journal.pone.0049924

Rosenblum, E.B., Stajich, J.E., Maddox, N., Eisen, M.B., 2008. Global gene expression profiles for life stages of the deadly amphibian pathogen Batrachochytrium dendrobatidis. Proc. Natl. Acad. Sci. U. S. A. 105, 17034-17039. https://doi.org/10.1073/pnas.0804173105

Santos, A.L.S. dos, 2011. Protease expression by microorganisms and its relevance to crucial physiological/pathological events. World J. Biol. Chem. 2, 48-58. https://doi.org/10.4331/wjbc.v2.i3.48

Scheele, B.C., Pasmans, F., Skerratt, L.F., Berger, L., Martel, A., Beukema, W., Acevedo, A.A., Burrowes, P.A., Carvalho, T., Catenazzi, A., De la Riva, I., Fisher, M.C., Flechas, S. V, Foster, C.N., Frías-Álvarez, P., J Garner, T.W., Gratwicke, B., Guayasamin, J.M., Hirschfeld, M., Kolby, J.E., Kosch, T.A., La Marca, E., Lindenmayer, D.B., Lips, K.R., Longo, A. V, Maneyro, R., McDonald, C.A., Mendelson III, J., Palacios-Rodriguez, P., Parra-Olea, G., Richards-Zawacki, C.L., 
Rödel, M.-O., Rovito, S.M., Soto-Azat, C., Felipe Toledo, L., Voyles, J., Weldon, C., Whitfield, S.M., Wilkinson, M., Zamudio, K.R., Canessa, S., 2019. Amphibian fungal

panzootic causes catastrophic and ongoing loss of biodiversity. Science 363, 1459-1463. https://doi.org/10.1126/science.aav0379

Schloegel, L.M., Toledo, L.F., Longcore, J.E., Greenspan, S.E., Vieira, C.A., Lee, M., Zhao, S., Wangen, C., Ferreira, C.M., Hipolito, M., Davies, A.J., Cuomo, C. a, Daszak, P., James, T.Y., 2012. Novel, panzootic and hybrid genotypes of amphibian chytridiomycosis associated with the bullfrog trade. Mol. Ecol. 21, 51625177. https://doi.org/10.1111/j.1365-294X.2012.05710.x

Stergiopoulos, I., Zwiers, L.H., De Waard, M.A., 2002. Secretion of natural and synthetic toxic compounds from filamentous fungi by membrane transporters of the ATPbinding cassette and major facilitator superfamily. Eur. J. Plant Pathol. 108, 719734. https://doi.org/10.1023/A:1020604716500

Supek, F., Bošnjak, M., Škunca, N., Šmuc, T., 2011. Revigo summarizes and visualizes long lists of gene ontology terms. PLoS One 6, e21800. https://doi.org/10.1371/journal.pone.0021800

Veal, E.A., Toone, W.M., Jones, N., Morgan, B.A., 2002. Distinct roles for glutathione Stransferases in the oxidative stress response in Schizosaccharomyces pombe. J. Biol. Chem. 277, 35523-35531. https://doi.org/10.1074/jbc.M111548200

Voyles, J., Woodhams, D.C., Saenz, V., Byrne, A.Q., Perez, R., Rios-Sotelo, G., Ryan, M.J., Bletz, M.C., Sobell, F.A., Mcletchie, S., Reinert, L., Rosenblum, E.B., RollinsSmith, L.A., Ibáñez, R., Ray, J.M., Griffith, E.J., Ross, H., Richards-Zawacki, C.L., 2018. Shifts in disease dynamics in a tropical amphibian assemblage are not due to 
756 pathogen attenuation. Science 359, 1517-1519.

757 https://doi.org/10.1126/science.aao4806

758 Xie, X.Q., Wang, J., Huang, B.F., Ying, S.H., Feng, M.G., 2010. A new manganese

759 superoxide dismutase identified from Beauveria bassiana enhances virulence and 760 stress tolerance when overexpressed in the fungal pathogen. Appl. Microb. Cell 761 Physiol. 86, 1543-1553. https://doi.org/10.1007/s00253-010-2437-2

762 Youseff, B.H., Holbrook, E.D., Smolnycki, K.A., Rappleye, C.A., 2012. Extracellular 763 superoxide dismutase protects Histoplasma yeast cells from host-derived oxidative 764 stress. PLoS Pathog. 8, e1002713. https://doi.org/10.1371/journal.ppat.1002713 


\section{Figure captions}

Figure 1. Principal components analysis of all $B d$ samples based on $\log _{2}$ transformed counts per million gene transcripts. Biological replicates cluster by isolate ID, and isolates cluster by lineage on the first axis.

Figure 2. Heatmap of gene expression differences between Bd-Brazil (CLFT001 \& CLFT044) and Bd-GPL (CLFT023, CLFT026, JEL410, JEL422) based on sample to sample Euclidean distances calculated from $\log _{2}$ and $z$-score transformed count data. Negative z-scores indicate decreased expression; positive z-scores indicate increased expression.

Figure 3. Expression values of putative $B d$ pathogenesis genes that are significantly differentially expressed between $B d$-Brazil and $B d$-GPL ( $\log F C>1$, FDR-corrected $\mathrm{p}<0.05)$. Aspartic-type peptidase genes tend to be increased in $B d$-Brazil, CBM18 (carbohydrate binding module 18) and GST (glutathione s-transferase) genes tend to be decreased. SODs (superoxide dismutase), M36 metalloprotease, and serine-type peptidase genes show more variable expression. Boxplots show gene expression values for each isolate measured as $\log _{2}$ transformed reads per kilobase per million reads (RPKM). All genes except BDEG_23910 show significant differential expression between $B d$-Brazil and $B d$-GPL regardless of JEL422 inclusion.

Figure 4. Expression values of representative genes related to membrane composition, transmembrane transport, and ciliary structure that are significantly differentially 
expressed between JEL422 and remaining Bd-GPL isolates (logFC>1, FDR-corrected $\mathrm{p}<0.05)$. All genes are significantly increased in JEL422 relative to other $B d-G P L$ isolates. Boxplots show gene expression values measured as $\log _{2}$ transformed RPKM, as in Figure 3. Genes with * indicate significant differential expression in both JEL422 Bd-GPL and JEL422 Bd-Brazil pairwise comparisons. Genes with a indicate significant differential expression in both JEL422 Bd-GPL and JEL422 JEL410 comparisons. 


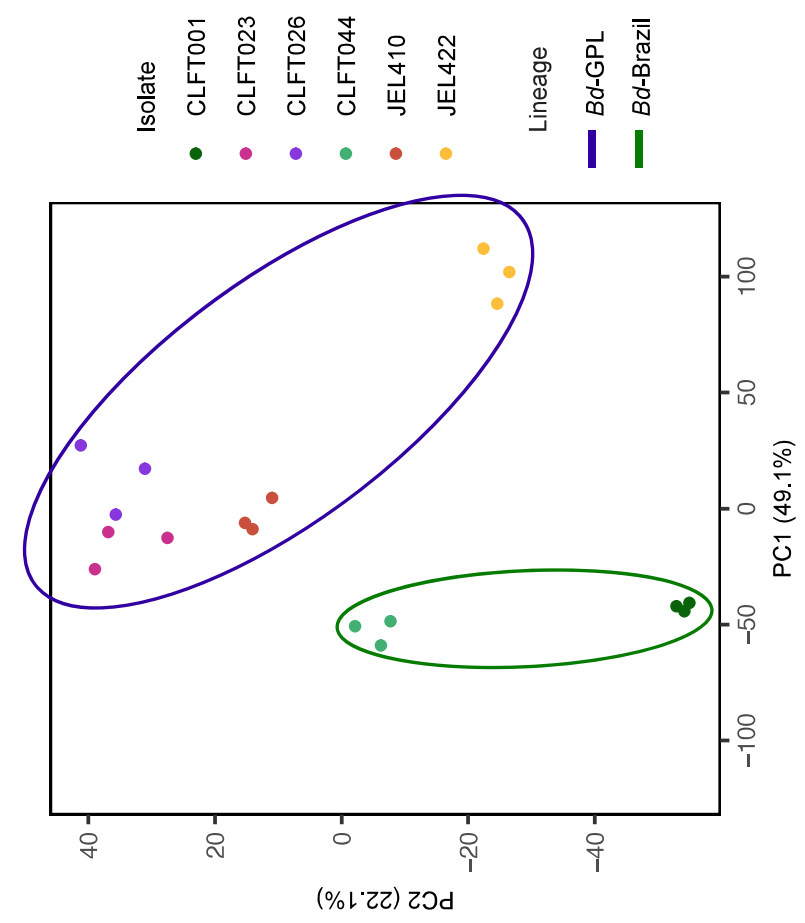




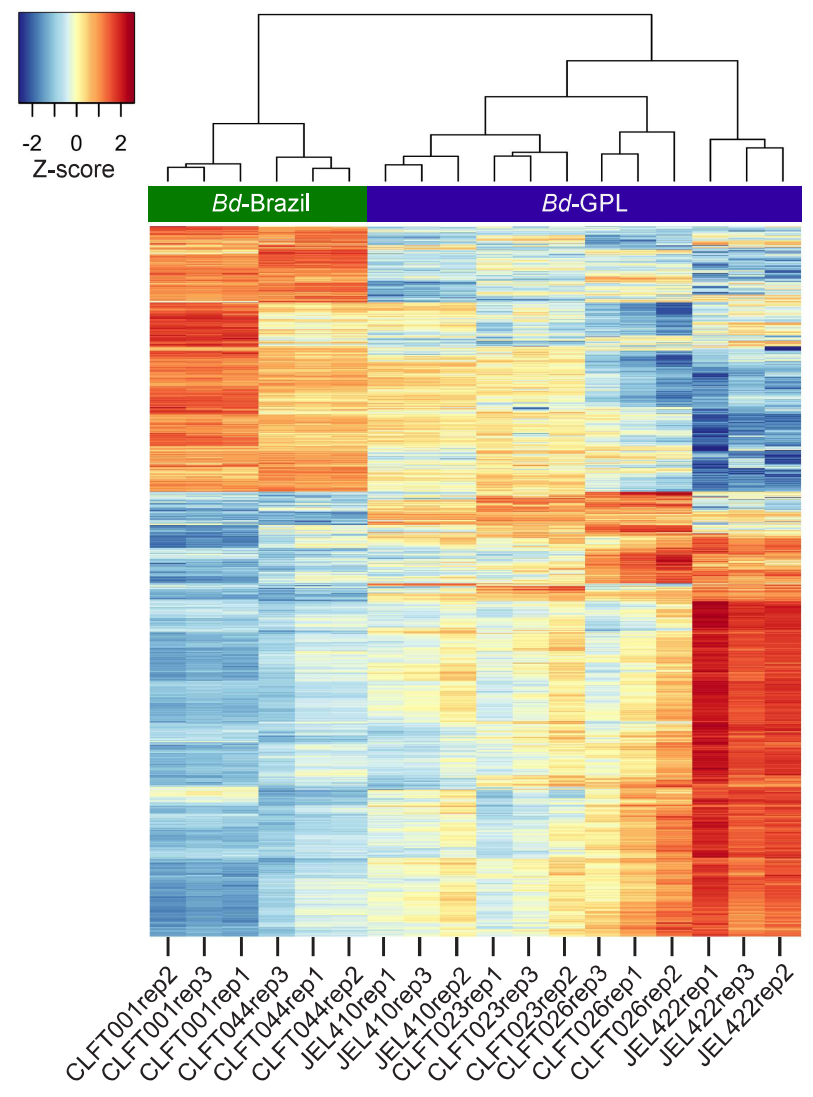



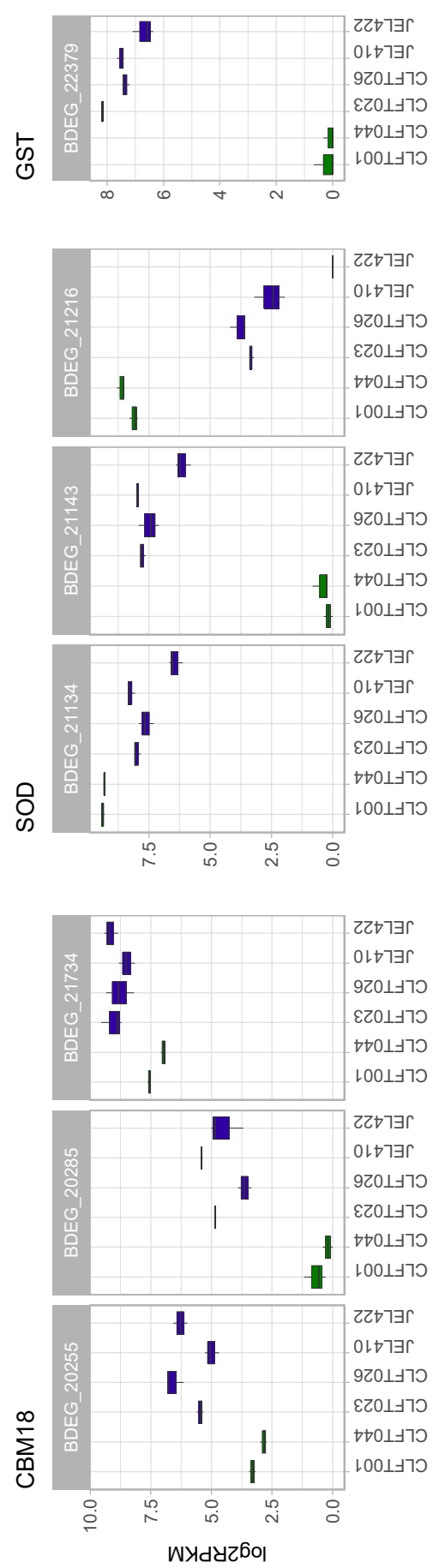
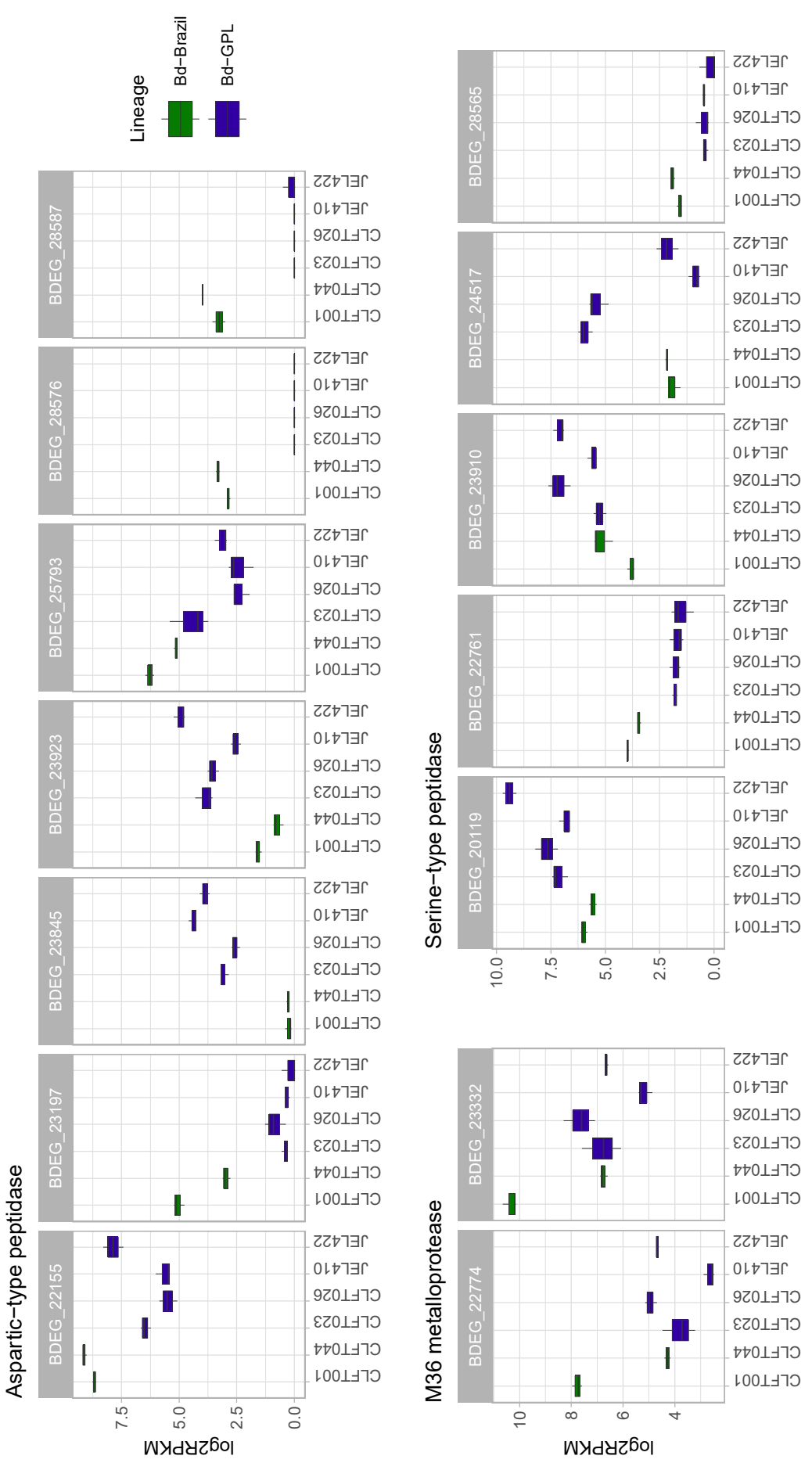

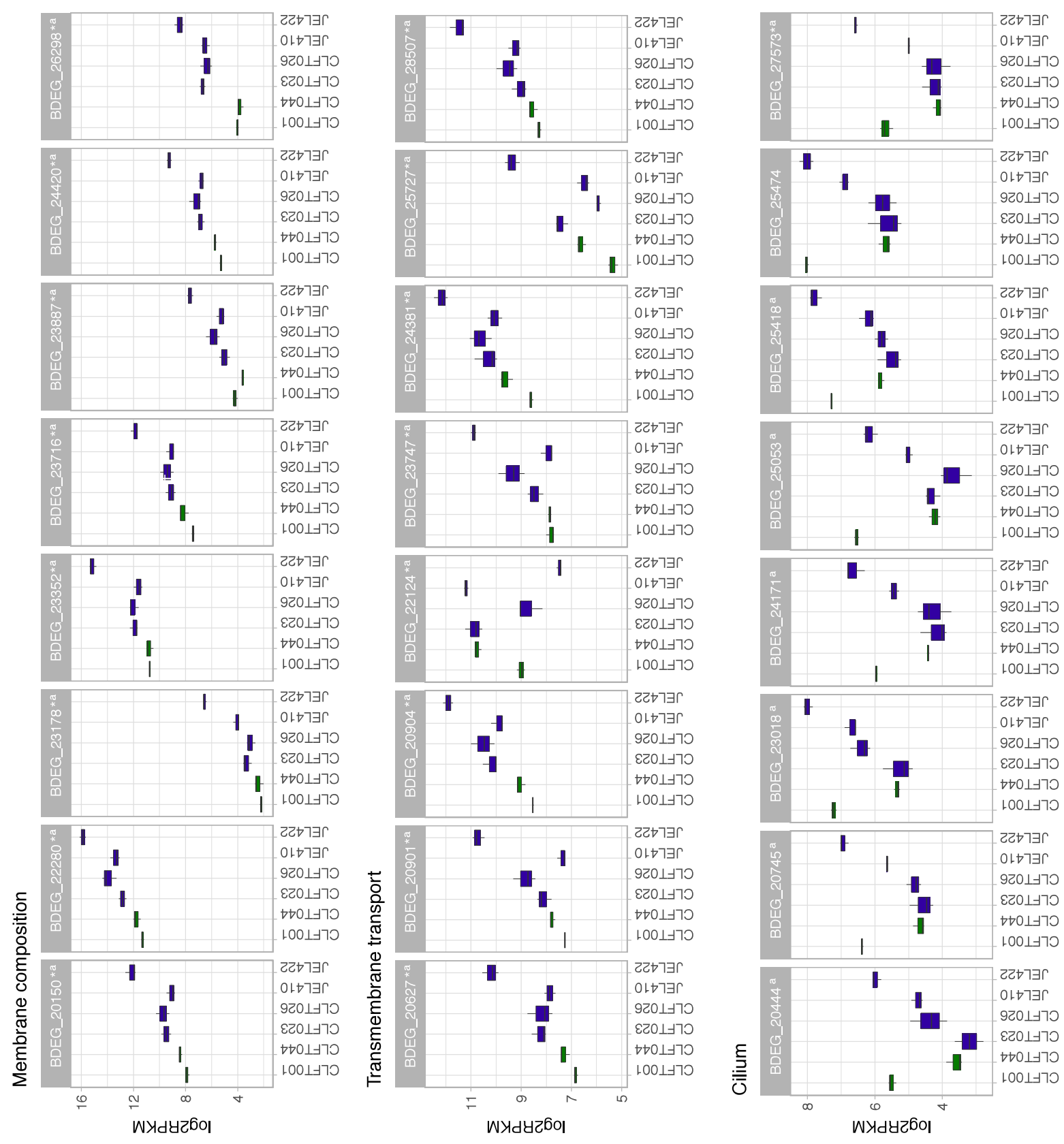


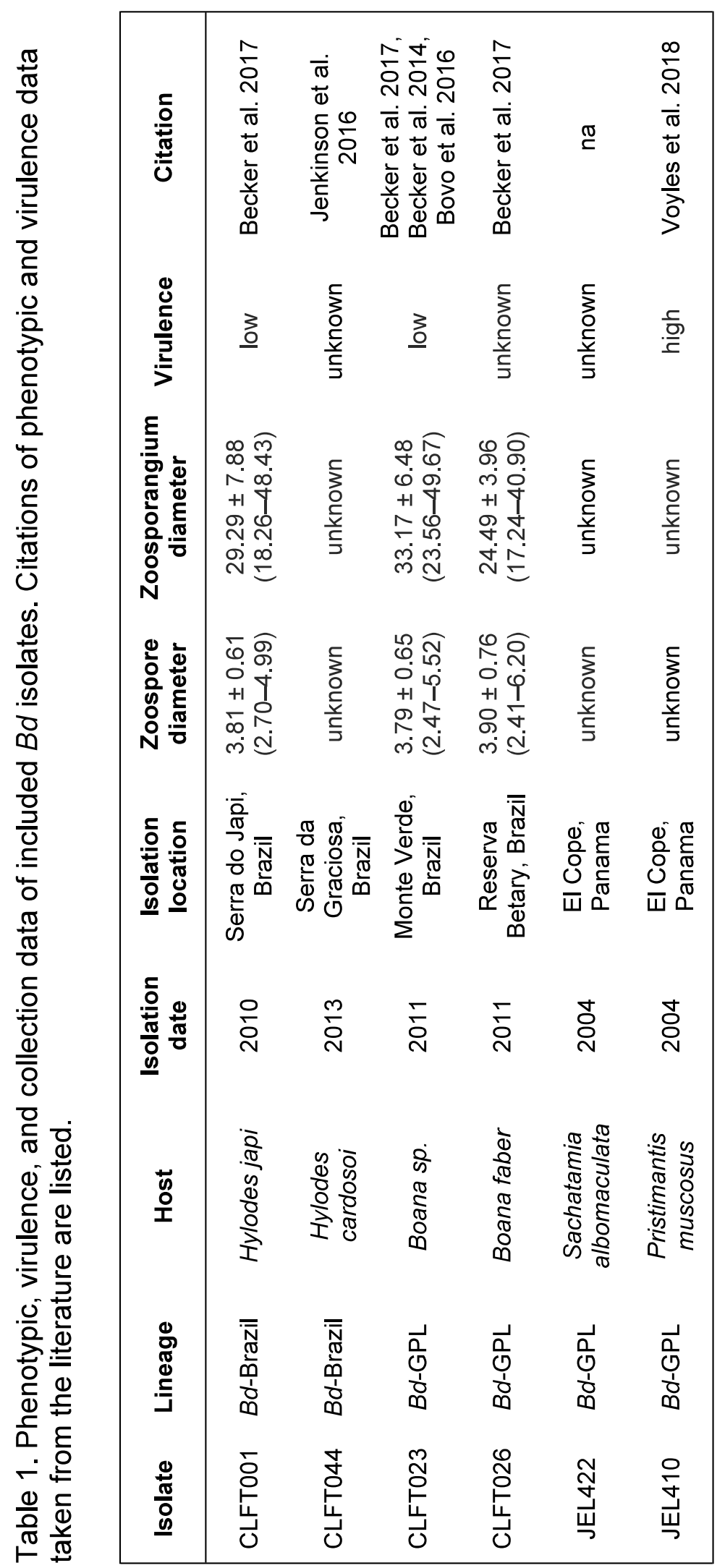


Table S1. $B d$ isolate sequencing and mapping data.

\begin{tabular}{|c|c|c|c|c|}
\hline Isolate ID & $\begin{array}{c}\text { Raw read } \\
\text { number }\end{array}$ & $\begin{array}{c}\text { Trimmed read } \\
\text { number }\end{array}$ & $\begin{array}{c}\text { Aligned read } \\
\text { number }\end{array}$ & $\begin{array}{l}\text { Percent } \\
\text { alignment }\end{array}$ \\
\hline CLFT001 & $14,151,397$ & $12,877,872$ & $11,601,245$ & $90.09 \%$ \\
\hline CLFT001 & $21,365,542$ & $19,449,597$ & $17,562,345$ & $90.30 \%$ \\
\hline CLFT001 & $30,196,492$ & $27,614,210$ & $25,157,345$ & $91.10 \%$ \\
\hline JEL410 & $21,736,680$ & $19,800,703$ & $18,355,395$ & $92.70 \%$ \\
\hline JEL410 & $26,105,280$ & $23,859,269$ & $22,014,537$ & $92.27 \%$ \\
\hline JEL410 & $28,334,266$ & $25,970,366$ & $24,121,364$ & $92.88 \%$ \\
\hline CLFT044 & $28,788,989$ & $26,315,319$ & $24,207,596$ & $91.99 \%$ \\
\hline CLFT044 & $24,871,983$ & $22,727,127$ & $20,993,698$ & $92.37 \%$ \\
\hline CLFT044 & $33,487,256$ & $30,568,947$ & $28,247,933$ & $92.41 \%$ \\
\hline CLFT026 & $21,958,817$ & $20,115,135$ & $18,584,272$ & $92.39 \%$ \\
\hline CLFT026 & $11,851,598$ & $10,842,369$ & $10,057,217$ & $92.76 \%$ \\
\hline CLFT026 & $12,545,704$ & $11,461,781$ & $10,552,124$ & $92.06 \%$ \\
\hline CLFT023 & $27,645,445$ & $25,248,816$ & $23,275,766$ & $92.19 \%$ \\
\hline CLFT023 & $31,535,685$ & $28,748,893$ & $26,450,468$ & $92.01 \%$ \\
\hline CLFT023 & $13,171,446$ & $12,008,917$ & $11,067,022$ & $92.16 \%$ \\
\hline JEL422 & $7,945,754$ & $7,211,686$ & $6,587,988$ & $91.35 \%$ \\
\hline JEL422 & $9,162,860$ & $8,272,822$ & $7,563,176$ & $91.42 \%$ \\
\hline JEL422 & $14,181,411$ & $12,979,691$ & $11,906,944$ & $91.74 \%$ \\
\hline $\begin{array}{l}\text { Total read } \\
\text { number }\end{array}$ & $379,036,605$ & $346,073,520$ & $318,306,435$ & \\
\hline
\end{tabular}


Figure S1. Expression values of all aspartic-type peptidase genes that are significantly differentially expressed between $B d$-Brazil and $B d$-GPL (logFC>1, FDR-corrected $\mathrm{p}<0.05)$. Aspartic-type peptidases tend to show increased expression in $B d$-Brazil relative to $B d$-GPL. Boxplots show gene expression values measured as $\log _{2}$ transformed RPKM, as in Figure 3.

Figure S2. Lineage-specific functional enrichment of $B d$ gene expression. Histograms depict significantly enriched Gene Ontology (GO) terms in the test set (increased expression in $B d$-Brazil or $B d$-GPL) relative to the reference set (annotated JEL423 genome). A. Genes with increased expression in Bd-Brazil (green) vs. Bd-GPL (purple). B. Genes with increased expression in Bd-Brazil (green) vs. Bd-GPL (purple), with JEL422 removed. GO terms are partitioned by category $(C=$ cellular component, $\mathrm{P}=$ biological process, $\mathrm{F}=$ biological function). Bolded $\mathrm{GO}$ terms are shared between enrichment tests.

Figure S3. Inter- and intra-lineage functional enrichment of JEL422. Histograms depict significantly enriched Gene Ontology (GO) terms in the test set (increased expression in $B d$-Brazil, $B d$-GPL, or JEL422) relative to the reference set (annotated JEL423 genome). A. Genes with increased expression in Bd-Brazil (green) vs. JEL422 (yellow). B. Genes with increased expression in Bd-GPL (purple) vs. JEL422 (yellow). GO terms are partitioned by category $(\mathrm{C}=$ cellular component, $\mathrm{P}=$ biological process, $\mathrm{F}=$ biological function). Bolded GO terms are shared between enrichment tests. 
Figure S4. Functional enrichment of Panamanian epizootic isolates. Histograms show genes with increased expression in JEL410 (red) vs. JEL422 (yellow). Histograms depict significantly enriched Gene Ontology (GO) terms in the test set (increased expression in JEL410 or JEL422) relative to the reference set (annotated JEL423 genome). GO terms are partitioned by category $(\mathrm{C}=$ cellular component, $\mathrm{P}=$ biological process, F=biological function). 


\section{Hit}

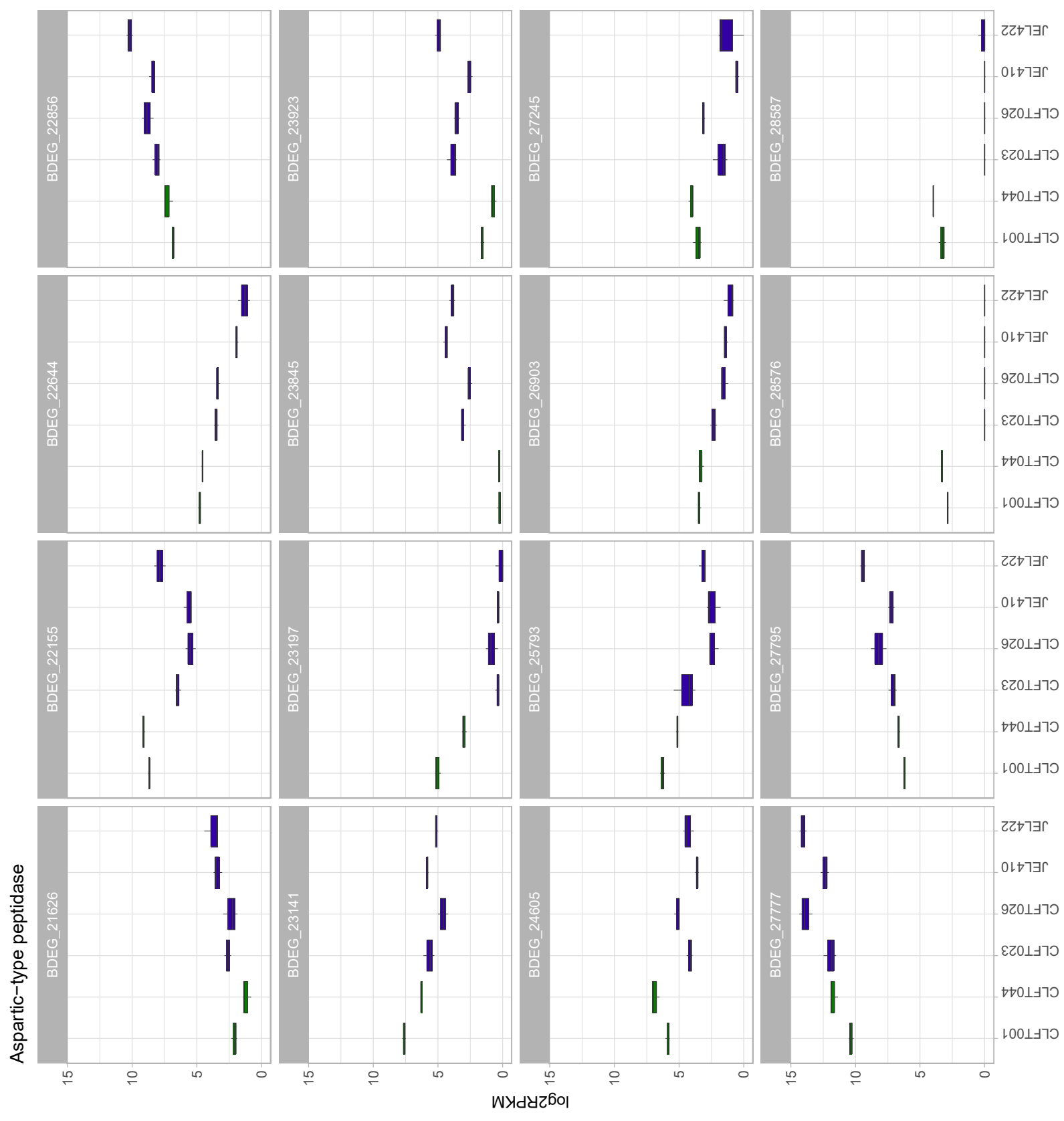



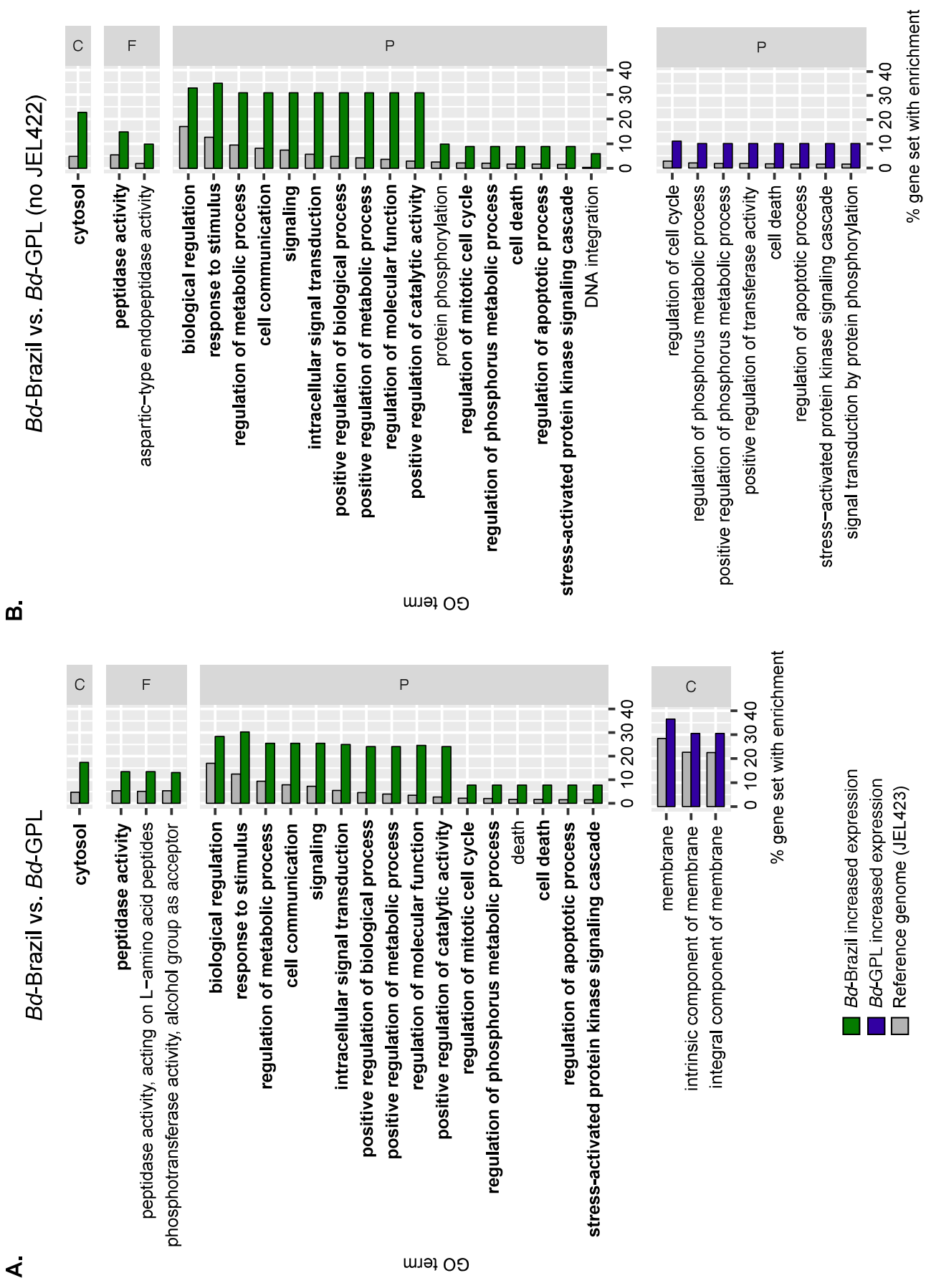

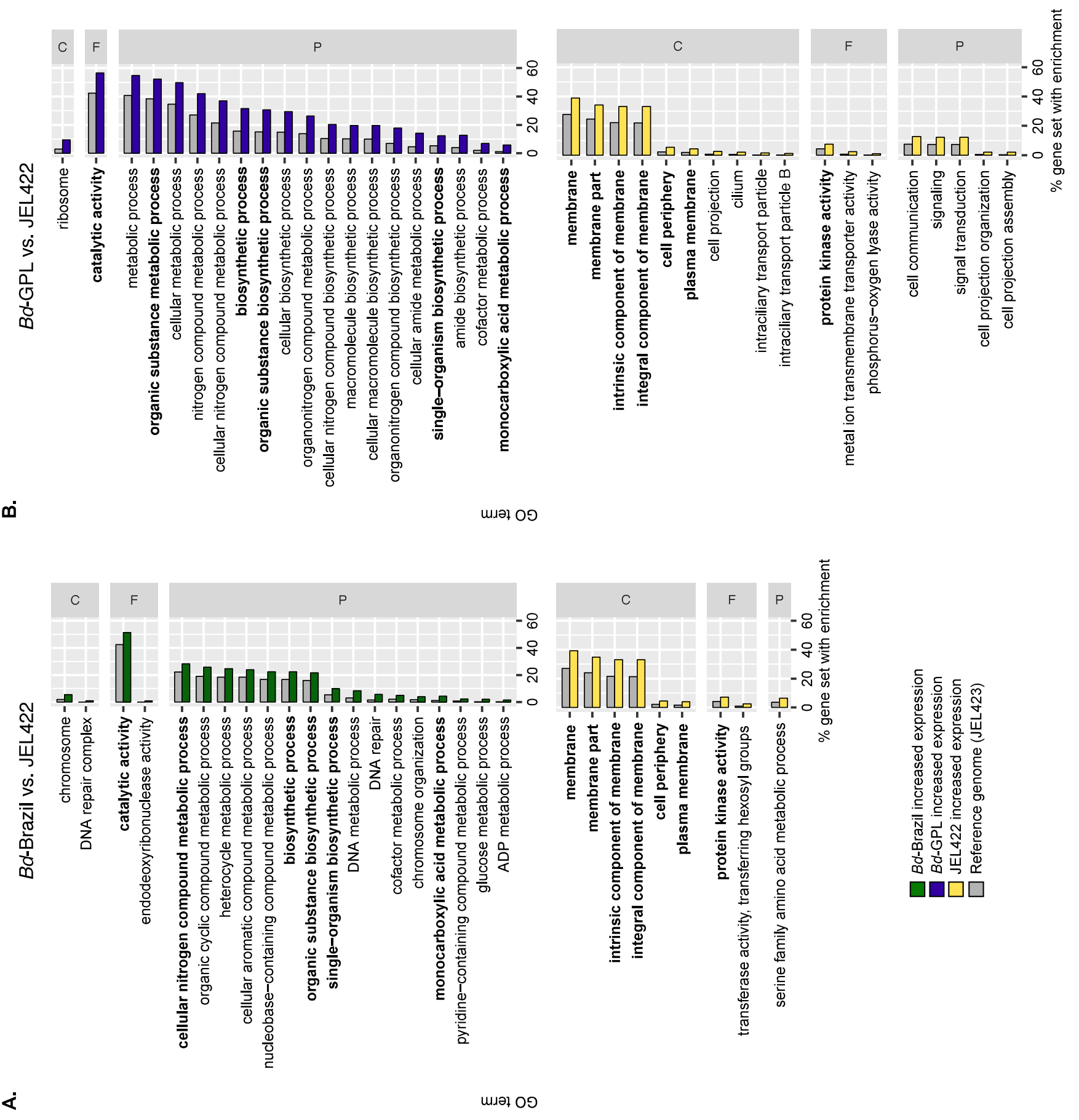


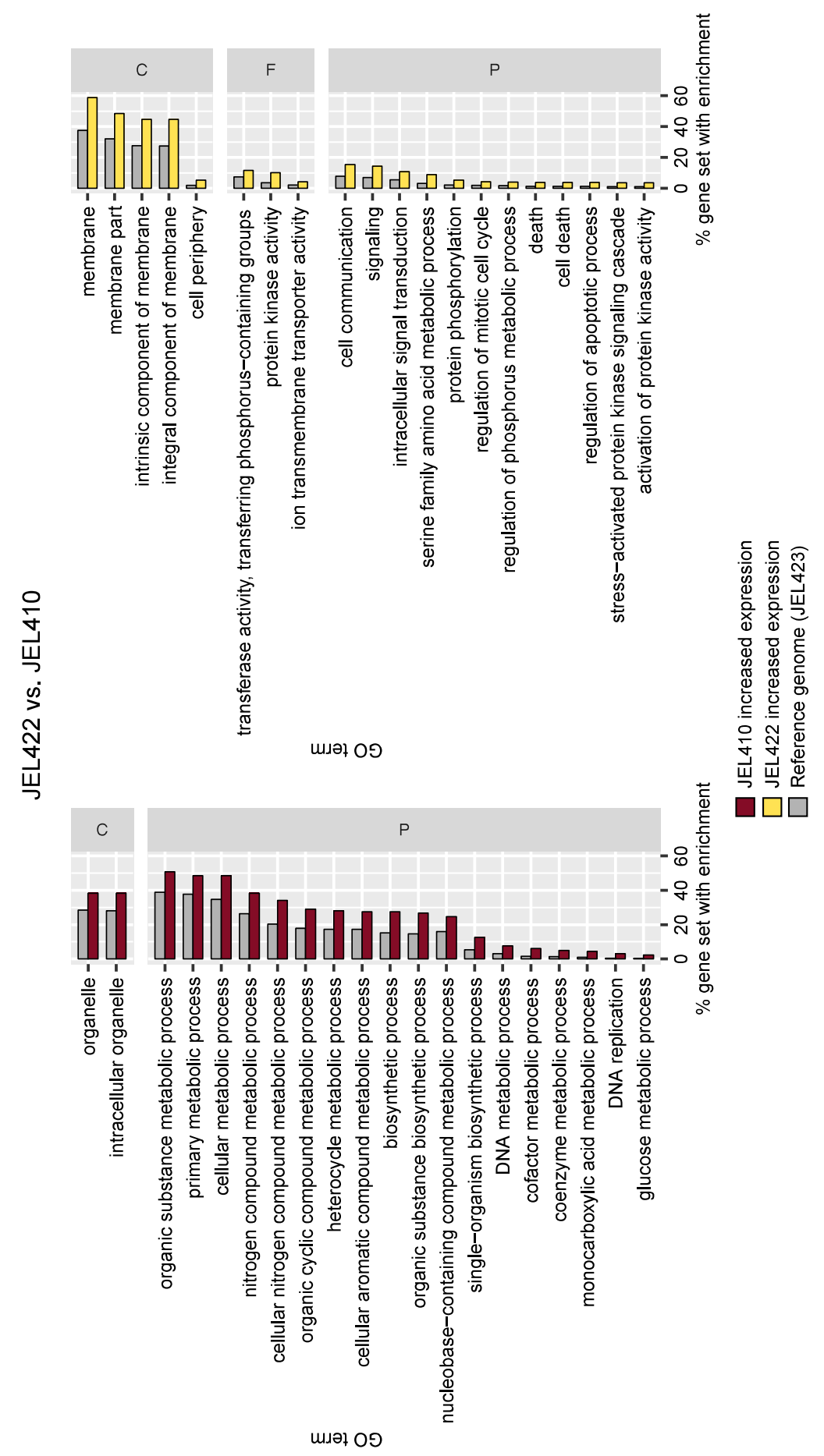

